\title{
Building future primary teachers' capacity in STEM: based on a platform of beliefs, understandings and intentions
}

\author{
Premnadh M. Kurup ${ }^{1 *}$, Xia Li ${ }^{2}$, Greg Powell ${ }^{1}$ and Michael Brown ${ }^{1}$
}

\begin{abstract}
Background: STEM education needs to begin in primary schools and should aim to prepare young people for active participation in their future. To produce a generation interested and skilled in STEM, the key foci within schools may best occur through teams of teachers working together in an integrated approach, based on crosscurricular teaching and learning. Teachers play a key role in STEM education, and it is important to attract high achievers with relevant backgrounds into teaching. This research study focused on the beliefs, understandings, and intentions of pre-service primary teachers to teach STEM. These beliefs, understandings, and intentions form the platform on which the pre-service teachers build their capacity to teach STEM subjects in primary schools.

Results: The data $(n=119)$ collected from a designed questionnaire were analysed qualitatively and quantitatively. An interpretive practice has been used in formulating categories based on responses regarding beliefs, understandings, intentions, and ideal scenarios for future practices and a grounded theory approach for formulating scenarios based on data analysis. The qualitative data were coded into categories based on responses. Structural equation modelling (SEM) and logical regression were conducted to find relationships of the pre-service teacher's platform for capacity building and connecting to what is required in their classrooms now and in the future. Logistic regressions were used to explore the association of all the questionnaire items and open responses related to the platform and future capacity building. Based on the results, it is evident that the platform developed for teaching STEM based on experience in their teaching degree is limited; however, they have positive intentions to take up STEM. They are not seeing any positive initiative at schools, and they have limited confidence to teach STEM. However, they were suggesting that they should be provided with more opportunities to teach STEM.

Conclusions: Overall, our findings indicate that pre-service teachers do not have strong understanding; however, they have strong beliefs and intentions to teach STEM in their future career. The results of this study indicate that the capacity they have built provides them with explicit views on how to teach STEM in primary schools now and informs what they need for the future teaching of STEM. It is essential to formulate a course work and professional development in STEM, capable of integrating disciplines, providing an understanding of pedagogical approaches, and connecting to real-life relevance with the twenty-first century competencies.
\end{abstract}

Keywords: Integrated STEM teaching, Intention to teach STEM, Platform and capacity building in STEM, Pre-service teacher education, STEM education

\footnotetext{
* Correspondence: p.kurup@latrobe.edu.au

${ }^{1}$ School of Education, College of Arts, Social Sciences and Commerce (ASSC),

La Trobe University, Bundoora, Melbourne, VIC 3086, Australia

Full list of author information is available at the end of the article
} 


\section{Introduction}

What is taught in schools is based on thoughtful considerations about what young people will need in order to grow, develop, and thrive as they meet the challenges associated with their lives. While young people must be able to react in strategic ways to these challenges, they need to also be proactive and drive change. They need to be equipped to design the future. Obviously, this is a big ask for schools, but it is a requirement of a democratic society that needs to be met (Kalantzis and Cope 2012). An education for the twenty-first century demands skills in science, technology, engineering, and mathematics (STEM) to deal with challenging complex situations, and these capabilities need to be developed from as early as primary school (NRC 2015). Early interest and appropriate experiences can influence and foster interest in STEM. Integrated approaches to teaching and learning and teacher preparation are key aspects to be focused on to produce a responsible generation that is interested and skilled in STEM. It is important to attract high achievers and boost the rigour of STEM within primary school teaching and pre-service teacher preparations (Prinsley and Johnston 2015). Pre-service teachers need subject matter knowledge, pedagogical content knowledge (PCK), and expertise to innovate and deal with STEM in their own future classrooms (Abell 2007, 2008). Further, there is a need in pre-service teacher education to deal with PCK development as an opportunity for creative and innovative practices in classrooms. Professional learning should be able to translate to a professional knowledge competency to deal with STEM in their future teaching (Berry et al. 2008; Lee et al. 2007).

Current practices, education goals, and policies of STEM education internationally lack a proper framework at the moment and need a greater focus for producing technologically competent and informed citizens (Zeidler 2016). Many of the stakeholders in society are advocating for the need for STEM knowledge and capabilities to be developed at school. STEM capabilities are defined as the capabilities that are derived from an integration and synthesis of knowledge bases from what has previously been separate specialised disciplines and bodies of knowledge, i.e. science, technology, engineering and mathematics. Organisations like the Foundation for Young Australians (FYA) have conducted and disseminated research to suggest that a new work order is emerging and that as many as $75 \%$ of all the jobs in the future will involve STEM capabilities (Foundation for Young Australians 2017). Accordingly, there is an urgent need to educate our students, parents, and teachers about STEM-related challenges to deal with lifestyle and workplace changes using efficient and viable technologies (Tobin 2016). STEM has significance in everyday practices, valorisation of knowledge, language choice, and different forms of engagement of individuals. Different domains of STEM practice for everyday life, school, and STEM disciplines are required (Civil 2016).

The workplace of the future is being variously described as Industry 4.0 (Germany and Europe), Industrial Internet Consortium (USA), and Industrial Value Chain Initiative (Japan and Asia). These terms refer to developing approaches to work where whole supply chains, work, and production processes are enhancing efficiency and effectiveness through increased digitalisation. Increasingly, workplaces are using sensors and actuators to fine-tune and regularise their workflow and processes. A never-ending flow of data is being collected and turned into digital information. This information is being communicated across the internet and cloud computing systems. The workers in these workplaces are utilising this information making decisions and taking appropriate actions. Hence, Industry 4.0 is about generating and collecting data as digital information from across a network of stages and steps in the value chain that is all interconnected. It includes an increasing use of automation, robotics, digital information, big data, the internet, large-scale computing, and cyber-social systems (Graube and Mammes 2018). In STEM education, these aspects connect with the six principles identified by Falk et al. (2016) for improving STEM learning and generate interest among primary and secondary school children for their capacity building. The six principles are as follows: learning should reflect a lifelong process; STEM content is worth learning, examine learning as a cultural process involving everyday experiences, involve practitioners and learners in the research process, emerging technology and new needs will continue to shape contents and practices of STEM, and considerations should be given to broader sociocultural and political contexts. STEM should provide skills and capacity for individuals to deal with modern life efficiently in terms of technology, science, and ethics. Media and technologies provide major influences in understanding the world including knowledge and interest in subjects, and learning in school and in out-of-school contexts (Falk and Needham 2013; NRC 2015). More recently the idea of an educational infrastructure has been reframed by STEM educators using the concept of ecosystem of social networks, peers, educators, friends, and families for in school and out-of-school contexts of learning (NRC 2015).

It is also important to empower students to deal responsibly with issues associated with changing and appropriate use of technology, and education should address understanding as well as societal implications of democratic informed decisions and actions (Schreiner et al. 2005). Likewise, Perkins (2014) uses the concept of "life-worthy learning" to discuss an approach to 
educating young people for a changing world. Levinson et al. (2012) argue that if students are provided with authentic scenarios in which decision-making involves considerations of different viewpoints, they will be more responsible and look to make democratic decisions. In reality, students should be capable of using their knowledge, not just in a scientific context but also for societal and environmental needs (Fernández-Manzanal et al. 2007), and Slaughter's (1996) categories for future planning scenarios of predict, prefer, possible, promise, and precedent will prove a useful framework in civic democratic decision-making. It is a big ask for our teachers and our schools to prepare our young people for these contemporary and future workplaces-this is their mission. Curriculum decisions are being made about what preparing our students for these workplaces looks like in the context of primary, secondary, and post-compulsory education. But at the very least, it will involve key aspects of digital literacy such as writing code and analysing and representing data. In addition, it will also involve reasoning, making judgements, problem-solving, decision-making, and communication skills (Foundations for Young Australians 2015; Hajkowicz et al. 2016). With this in mind, this current study asks primary teachers how well prepared they feel they are to teach STEM. Future primary teachers should have competency and confidence to teach STEM education connected to the daily lives of their learners.

Future teachers are expected to have clarity with coursework, understanding of pedagogy, and performance indicators. All forms of STEM experiences such as school-based activities and out-of-school activities like workplace visits play a vital role in a successful education program (Shah et al. 2018). Further, a real-life relevance and its connections to school programmes could, in the long run, help future STEM workforce with the twenty-first century competencies focused on innovations (Kitchen et al. 2018).

\section{Conceptual framework}

STEM education policies should make clear concept and procedural connections for the purpose of developing instructional material and implementing teaching practices. This should be configured to the four-dimensional framework of purpose, policy, program, and practices formulated for STEM education by Bybee (2013). New research paradigm and approaches should be created by stepping back and looking more holistically at questions of the what, when, where, why, how, and with whom STEM learning is needed. These research designs need to cut across the diverse settings and investigate multiple contexts and media in which learners live and interact (Dierking and Falk 2016). Future STEM education and research needs to be positioned in the life-wide, life-deep, and life-long approach in terms of teaching and learning environment (Rahm 2016). A very practical approach includes using a suite of the twenty-first century skills to conceptualise and utilise information literacy using STEM education via science, mathematics, technology, and engineering practices (Storksdieck 2016).

Beliefs and understandings constitute clarity of scientific discourse and assessment of scientific information. Beliefs regarding issues influence a wide range of attitudes concerning science and technology and consequences of the impacts of human activities. Beliefs also lead to the understanding of a person being a part of the natural environment (Schultz 2001). The interpretation of scientific and technological issues associated with STEM not only requires a platform of scientific knowledge but also positively held beliefs about the reality and impacts (Thomm and Bromme 2012). Interdisciplinary approaches to democratic civic informed decision-making (Johnson and Adams 2011) align with the Next Generation Science Standards (NGSS Lead States 2013) and National Research Councils' focus on integrating divergent thinking and lead to democratic civic practices for informed decision-making scenarios in classrooms. Such approaches involve different ways of thinking, solving problems, and communicating. Students learn to use a range of technologies to plan, analyse, evaluate, and present their work. They learn the valuable reasoning and thinking skills that are essential for functioning both within and outside the school environment and about creativity, design principles, and processes involved. The nature of learning today is interactive, enabled through the use of the internet where schools take the initiative in designing active learning that emphasises the interaction rather than just the content (Anderson 2004).

Many issues in STEM education are very complex, and solutions require political, economic, cultural, social, and individual decisions and actions. School science programs should provide for societal participation as a potential for life-long participation in STEM learning that relates to the many varied societal issues faced by our societies today. In this process, teachers and students are required to extend their knowledge of science procedures and connect this to democratic civic decision-making (Fensham 2015, 2016). The knowledge gained from practical life-oriented and life-related situations and connecting these to daily life would provide students with confidence and competence to function effectively as informed citizens (Ryder 2001). An education program targeting STEM issues should encourage students to actively participate in societal issues investigating democratic civic decision-making by selecting suitable contexts that are related to the daily lives of 
students (Liu et al. 2011; Dede 2009 2013). This would provide uninterrupted lifelong learning related to what is important in the day-to-day life and cope with changes in their daily lives (Roth and Lee 2004). The application of Challenge Based Learning processes begins with a big idea (or issue), followed by an essential question, a challenge, guiding questions, activities, and resources, providing solutions through action based on reflection and assessment and finally publishing to a wider audience (Apple Inc. 2010).

It is important that teacher education focuses on producing teachers capable of dealing with STEM in their future classroom teaching and learning. This study focuses on identifying the basis of building capacity to teach STEM based on pre-service teachers' overall experience in their university teacher education program and utilises a two-tier conceptual framework for generating a platform (Walker 1971) for and identifying the capacity for pre-service teachers to deal with STEM in their future career. In these two tiers, aspects covered are four-dimensional STEM education (Bybee 2013), democratic decision-making, willingness of engaging STEM-related issues with ideas of disciplines, and contexts connected to daily life for human knowledge, inquiry, and design. These aspects build capacity in STEM for future teachers in developing programs that will connect to all disciplines with school-based and life-based scenarios. Internationally, there is an increasing trend to prepare STEM-focused schools and competent STEM teachers. Future teachers need to understand STEM for building confidence in teaching STEM which is integrated, interdisciplinary, and connected to the real world.

\section{Tier 1}

Pre-service teachers' beliefs, understanding, and intentions regarding STEM based on their present expertise from their course and professional practicum placements in schools will expand their platform to deal with STEM. The basis of this platform is formulated using pre-service teachers' beliefs, understandings, and intentions to teach STEM (Ajzen and Fishbein 1980). This platform is considered to enable pre-service teachers to build possible capacity to teach STEM with confidence and competence in their future teaching careers.

\section{Tier 2}

The aspects considered in tier 1 , which will contribute to capacity, is identified in the second tier where they are provided with specific aspects of how to build this capacity. Pre-service teachers provided details of what they observed and practised from the overall experience in their teacher education program which consists of university teaching and learning and professional experience of practicum in schools. They further suggested what they look forward to deal with STEM in their future classroom experience.

Figure 1 provides details and aspects covered in generating a platform and building capacity of pre-service teachers regarding STEM based on tiers 1 and 2.

\section{Purpose and research questions}

The purpose of this research was to investigate future primary school teachers' beliefs and understandings regarding STEM, their confidence to teach in this area, and their ability to engage in their future school settings. This is viewed from the perspective of their platform and capacity to deal with STEM in their teaching career. More specifically the research questions were as follows:

1. What beliefs, understandings, and intentions do pre-service primary teachers have about teaching STEM subjects in primary schools? (the platform that these future teachers' have for STEM education)

2. To what extent are pre-service primary teachers confident, competent, and prepared to teach STEM subjects in primary schools and what are their challenges? (future teachers' capacity to deal with STEM in their career)

\section{Methods}

\section{Instrument}

In this research, we studied the response of pre-service teachers based on a questionnaire using the theory of reasoned action (Ajzen and Fishbein 1980) and based on the aspects the Office of Chief Scientist of Australia identified for transforming STEM teaching in Australian primary schools (Prinsley and Johnston 2015). The instrument contained five items each on beliefs, understandings, and intentions to teach STEM on a 5-point Likert scale (1 strongly disagree to 5 strongly agree), and also, for each section, there were descriptive questions to position the capacity to deal with STEM and what is happening now as well as future needs (Kurup et al. 2017). This part generated tier 1 a platform of beliefs, understandings, and intentions to teach STEM, which led to tier 2 building capacity to teach STEM. The descriptive parts of the responses were related to what they believe, understand, and intended while teaching STEM in actual future practices. These responses were read and reread to make different categories, and these were coded accordingly.

\section{Participants}

This study is conducted among 119 pre-service teachers from an Australian University, in Melbourne, Australia (male 26, female 83, and 10 who chose not to disclose 


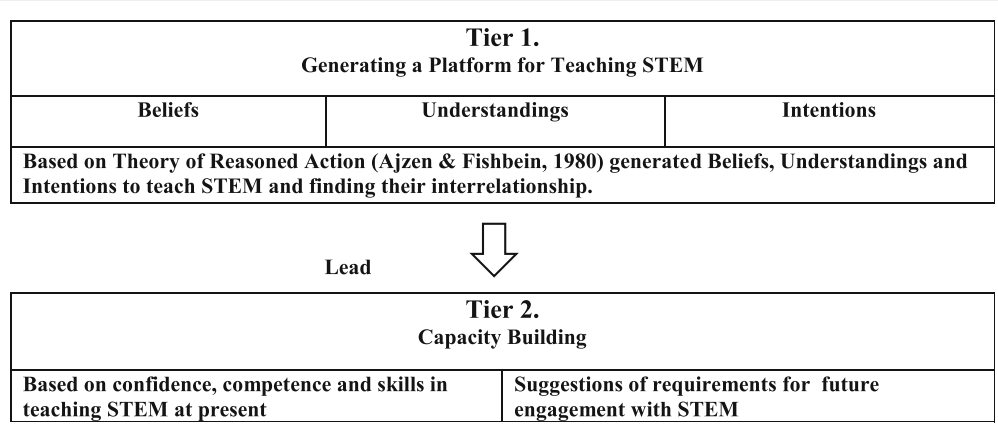

Fig. 1 Conceptual framework of future primary teachers' platform of capacity to deal with STEM in their future teaching

their gender; some of the pre-service teachers questioned the use of gender in such studies). These pre-service teachers had primary science, mathematics, and design and technology methods in their teaching programs.

\section{Qualitative and quantitative analysis Qualitative analysis}

Paper-based printed questionnaires were given to the participants and collected for analysis. All the descriptive parts of the questionnaire, such as future teachers' beliefs, understanding, intentions, and future expectation, were first read by one of the researchers and made into different categories. Samples of these were cross-checked by another researcher before frequencies of these categories were made by the researcher with expertise in statistics. This rigorous process generated categories in beliefs, understanding, intentions, what is happening now, and future needs. Categories in understanding will be from one among five categories, and details of these categories are described in Tables 1 and 2 . Categories are formulated based on written responses and are described in detail in the following analysis, results, and discussions. Categories formulated were found to be consistent with quantitative responses (tier1) and were thematic. An interpretive practice has been used in formulating categories based on responses regarding beliefs, understandings, intentions, and ideal scenarios for future practices (Holstein and Gabrium 2005). It was used as a grounded theory approach in formulating scenarios based on data analysis (Charmaz 2005).

\section{Statistical analysis}

The questionnaire items have been described elsewhere (Kurup et al. 2017). This study is focused on categorical open questions and first-described frequencies and percentages. Logistic regression models were used to explore the relationship between the response regarding what is happening now and future needs separately with the questionnaire items and the open question coded responses. To examine the more complex relationship among belief, understanding, and intention, partial least squares (PLS) estimation based structural equation model (SEM) was used. SEM is a largely confirmatory, rather than exploratory, technique to determine whether a certain model is valid. SEM is not only used to assess the structural model (path relationships among latent variables) but also to evaluate the measurement model (loadings of observed items on their latent variables). PLS is a well-established technique for estimating path coefficients in SEM accomplished using ordinary least squares (OLS) techniques which have minimal demands on measurement scales, sample size, and residual distributions (Chin and Newsted 1999). Hence, it is more

Table 1 Aspects of capacity building regarding STEM generated from qualitative responses

\begin{tabular}{|c|c|c|}
\hline \multicolumn{3}{|c|}{ Capacity building on STEM teaching and learning in primary schools } \\
\hline Beliefs about STEM & Positions of understanding STEM & Intentions of teaching STEM \\
\hline 1. Resources (BQ1) & $\begin{array}{l}\text { 1. Confidence and competence to teach STEM } \\
\text { (UQ1) }\end{array}$ & 1. Teach $S, T, E$, and $M$ in the curriculum (ITQ1) \\
\hline 2. Leadership and support (BQ2) & $\begin{array}{l}\text { 2. Confident with mathematics not with science } \\
\text { and technology to teach STEM (UQ2) }\end{array}$ & 2. Confident teachers in dealing with STEM (ITQ2) \\
\hline $\begin{array}{l}\text { 3. Experienced teachers, teacher } \\
\text { knowledge, and ability to integrate (BQ3) }\end{array}$ & $\begin{array}{l}\text { 3. Underprepared and lack of knowledge to teach } \\
\text { STEM (UQ3) }\end{array}$ & $\begin{array}{l}\text { 3. Student participation and activity-oriented teach- } \\
\text { ing and learning (ITQ3) }\end{array}$ \\
\hline 4. Team of teachers dealing STEM (BQ4) & $\begin{array}{l}\text { 4. Not confident with science to teach STEM } \\
\text { (UQ4) }\end{array}$ & $\begin{array}{l}\text { 4. Creativity, innovation, and interdisciplinary focus } \\
\text { in teaching and learning STEM (ITQ4) }\end{array}$ \\
\hline 5. Student-centred learning activities (BQ5) & 5. Not at all confident to teach STEM (UQ5) & $\begin{array}{l}\text { 5. STEM should be a specialised and compulsory } \\
\text { subject (ITQ5) }\end{array}$ \\
\hline
\end{tabular}


Table 2 The response generated from the qualitative data regarding what is happening now and future needs

\begin{tabular}{ll}
\hline Future teachers views of STEM & \\
\hline Now & Future needs \\
\hline $\begin{array}{l}\text { 1. Not effectively happening in } \\
\text { teaching and learning in schools } \\
\text { (N1) }\end{array}$ & $\begin{array}{l}\text { 1. Teacher knowledge and } \\
\text { capacity to teach STEM (F1) }\end{array}$ \\
$\begin{array}{ll}\text { 2. There is a push but no one is } \\
\text { clear about it (N2) }\end{array}$ & $\begin{array}{l}\text { 2. Teacher preparation and } \\
\text { professional development for } \\
\text { existing teachers (F2) }\end{array}$ \\
\begin{tabular}{ll} 
3. Happening only for namesake & $\begin{array}{l}\text { 3. The government should take } \\
\text { this a priority (F3) }\end{array}$ \\
\hline
\end{tabular}
\end{tabular}

suitable for research with small to medium samples and non-normal distributions. PLS method has gained interest and a corresponding increasing use among researchers (Chin 1998; Compeau and Higgins 1995). There is a set of standard goodness-of-fit index for PLS-SEM to measure reliability and validity. For a reflective measurement PLS-SEM, composite reliability (CR), which measures internal consistency, is considered acceptable if its value is greater than 0.7; similarly, factor loadings are also considered acceptable when they are greater than 0.7 and should be eliminated when they are below 0.4. The average variance extracted (AVE) is used to evaluate the discriminant validity and should also be greater than 0.5 for all latent variables. For a structural model, the path coefficients are evaluated first in terms of sign and significance by applying a bootstrapping test. The determination coefficient $R^{2}$ is then used to reflect the level or share of the composites' explained variance for established constructs. A bootstrapping procedure was adopted to assess statistical significance. In this study, the inner estimate of the standardised latent variable was accomplished through a path-weighting scheme, and 800 resamples were specified in the bootstrapping procedure.

\section{Results and discussions}

Generating a platform of beliefs, understandings, and intentions to teach STEM (tier 1)

This study examined beliefs, understandings, and intention to teach using five questions each on 5-point Likert scale. These aspects taken together are identifying a platform that the pre-service teachers have for STEM. The linking relationship between beliefs, understanding, and intentions to teach STEM recognises the overall picture of their views towards STEM and will contribute to their capacity to teach STEM in their future career. The questionnaire has the basic assumption underlying the theory of reasoned action that humans are quite rational and make use of all available information both personal and social before they act. Behaviour is defined as an overt action under an individual's volitional control and within the individual's capability (Ajzen and Fishbein 1980).

The questions were based on the position paper describing the need for transforming STEM teaching in Australian primary schools by the Office of the Chief Scientist of Australia (Prinsley and Johnston 2015). Questions on beliefs included about their beliefs regarding STEM in terms of importance, innovation, skills in future, and high-quality specialist teachers to teach in primary schools; questions on understanding focused on attracting high achievers to teaching, including STEM in teacher preparation, professional development, and leadership in primary schools; and questions on intentions to teach STEM included the interest connected to daily life, the ability to apply mathematics, the need for primary teachers to be supported by a specialist STEM teacher, the needs for separate subject on STEM in the university for pre-service teachers' university programs, and the teachers' ability in STEM to transform creativity and innovation among children.

Three latent factors were constructed according to the belief, understanding, and intention theory. We constructed an initial SEM model (Fig. 2) with those three latent factors and their corresponding indicators (B1 B5, U1 U5, IT1 IT5) as shown in Table 3.

Based on the initial PLS estimation result, factor loadings of B1 and B2 were all found below 0.4, so they were removed from the modified model (Fig. 3).

This diagram shows that there is a relationship between beliefs, understanding, and intentions to teach STEM among future pre-service teachers (Kurup et al. 2017). This is considered as tier 1 the platform. This platform provides a strongly held belief about the need of STEM for the changes in lifestyle practices. Their understandings of science, mathematics, and engineering are minimal and not enough to deal pedagogically to teach these subjects in classrooms; however, they have positive intentions to teach STEM. Further, they would be committed in their future teaching as they consider STEM-related issues important for life. This relationship is considered as the prequel to the present study of identifying the capacity building to teach STEM. The present study focuses on the pre-service teachers' platform from tier 1 towards their capacity to teach STEM in future career.

\section{Capacity building (tier 2)}

The major objective of this study is to identify capacity building towards dealing with STEM teaching in their career using their responses to open-ended questions in the questionnaire and connecting it to the quantitative responses (platform from tier1). The responses were read and reread to formulate into categories. It is observed that responses were provided with authenticity as 


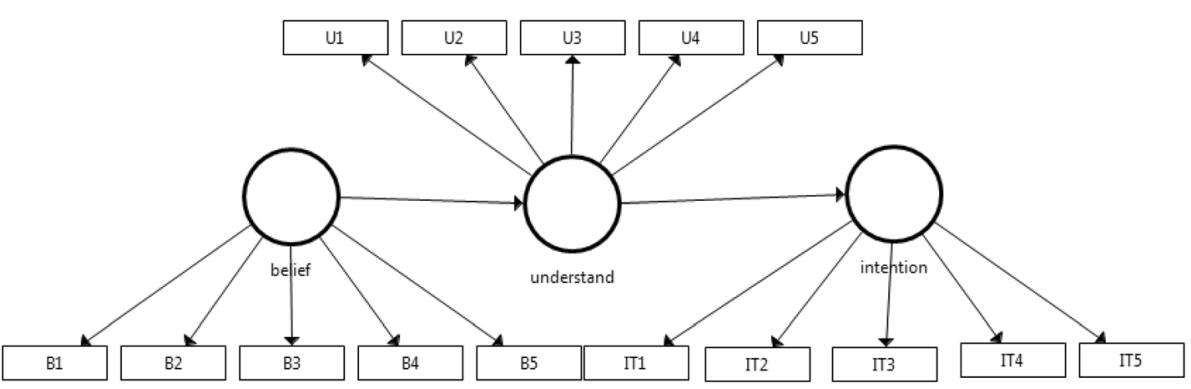

Fig. 2 Initial SEM model of STEM

they are based on the pre-service teachers' experience in professional placements in schools. Table 1 describes all categories formulated for beliefs, understanding, and intentions to teach STEM based on their descriptions from the responses.

The beliefs generated from pre-service teachers' written responses were focused on five themes; these are resources, leadership, expertise of teachers to integrate STEM, student-centred teaching, and team teaching for future teaching. Some pre-service teachers provided multiple responses in this category and some none. The pre-service teachers' understanding of their confidence tends to be reflected in one of the five categories only. This ranges from confident at present, confident to teach mathematics but not in science and technology, underprepared, not confident with science, and not at all confident to teach STEM. Intentions are focused on five categories such as curriculum; confident STEM teachers; student participation and activity-oriented teaching; creativity, innovation, and interdisciplinary approaches; and STEM should be a specialised subject. Intentions are also provided with sometimes multiple or no response by pre-service teachers.

They also provided responses to what is happening now and what they would like to do in the future. These responses are also based on their professional placement experience in schools and based on what they observe in schools, along with what they learned from their university courses. The descriptions of their views in building their confidence and competence to teach STEM in the future are provided in Table 2.

Based on their experience in professional placements and from the teaching and learning from the university, pre-service teachers perceived that at present STEM is not effectively taught or learned at the university in their teaching course or evident in their experience of professional placements in schools; however, they expressed that in the future, STEM should become a focus within teacher preparation, building STEM capacity, as aligned to government initiatives.

Table 4 and Fig. 4 describe the frequency of responses for beliefs, understandings, and intentions in terms of

Table 3 Latent factors and their indicators of beliefs, understandings, and intentions

\begin{tabular}{lll}
\hline Latent factors & Code & Indicators \\
\hline Belief & B1 & STEM education should begin in primary school. \\
B2 & We cannot be innovative and creative unless we have a quality education system. \\
B3 & STEM education can produce skills needed in the future. \\
B4 & Need high-quality teachers at all levels. \\
B5 & Primary schools needed specialist science, technology, and mathematics teachers. \\
Understanding & U1 & Attracting high achievers in STEM to primary school teaching. \\
& U2 & Boosting the science, technology, and mathematics. \\
& U4 & Should have a specialist STEM teacher. \\
U5 & Should be a national professional development. \\
Int & Primary school principals should be leaders in STEM. \\
IT2 & Teaching STEM will make teaching and learning more interesting and connected to daily life. \\
IT3 & Every primary teacher should be supported by a specialist STEM teacher to build effective STEM education. \\
IT4 & There should be a separate subject in university teacher education programs that are fully focused on STEM. \\
IT5 & Teachers ability, skills, and interest in STEM will transform creativity and innovation among children.
\end{tabular}




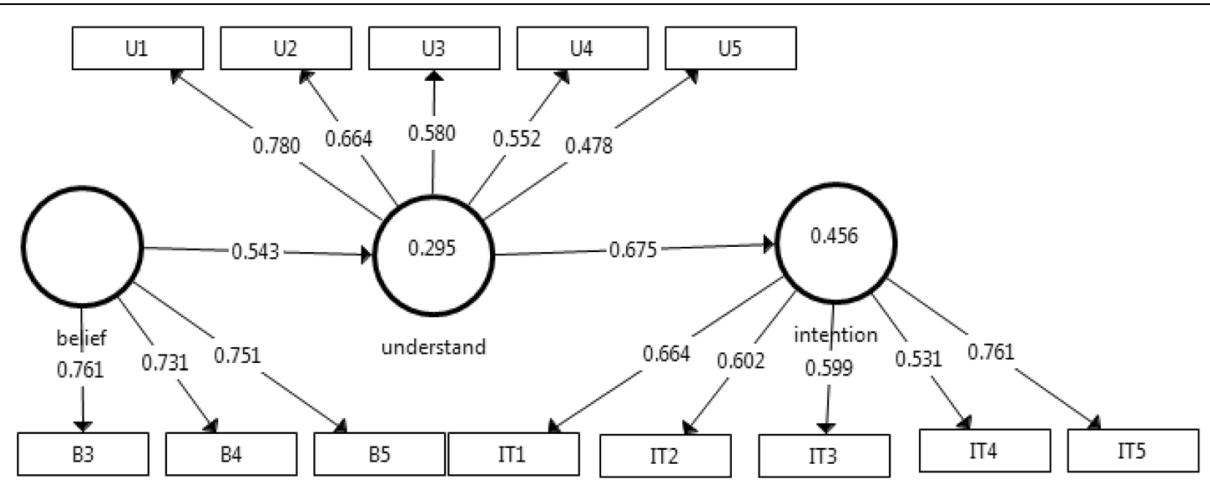

Fig. 3 Modified SEM model of STEM

open responses coded for their capacity building capability.

The platform generated based on the written responses from pre-service teachers indicated that they believe that resources, leadership, and teachers' ability to integrate are of high significance above $60 \%$ as shown in Table 4 and Fig. 4. Their overall understanding is very poor, and only less than $10 \%$ have understanding level 1 , which is the overall STEM understanding covering all aspects of STEM. Their intentions are found more than $50 \%$ on IQ1 to IQ4, and only IQ5 which is making it compulsory and everyday experience has less than $50 \%$ response. These responses were linked to what

Table 4 Frequency of description regarding belief, understanding, and intentions

\begin{tabular}{ll}
\hline Category of open question responses & $N(\%)$ \\
\hline Belief* $^{*}$ & $88(73.95)$ \\
Resources (BQ1) & $81(68.07)$ \\
Leadership and support (BQ2) & $76(63.87)$ \\
Experienced teacher and integrating STEM (BQ3) & $54(45.38)$ \\
Team teaching (BQ4) & $53(44.54)$ \\
Student-centred teaching (BQ5) & \\
Understanding** & $11(9.24)$ \\
Understanding一overall (UQ1) & $34(28.57)$ \\
Understanding一confidence in Maths (UQ2) & $27(22.69)$ \\
Understanding-underprepared (UQ3) & $15(12.61)$ \\
Understanding-no confidence in science (UQ4) & $32(26.89)$ \\
Understanding一not at all confident (UQ5) & $82(68.91)$ \\
Intention* & $73(61.34)$ \\
Teach S, T, E, and M (ITQ1) & $66(55.46)$ \\
Confidence of teachers (ITQ2) & $60(50.42)$ \\
Student-centred activities (ITQ3) & $53(44.54)$ \\
Creativity and interdisciplinary focus (ITQ4) \\
Compulsory and specialised STEM (ITQ5)
\end{tabular}

*Multiple Responses by one person

${ }^{* *}$ Categorised to only one of the category to overall responses pre-service teachers responded to with regard to what is happening now and their future needs.

Logistic regressions were used to explore the association of all the questionnaire items and open responses related to the platform (as in Table 5) and future capacity building (as in Table 6). From Table 5 univariate logistic regression, open responses in belief and intention are all positively related to platform descriptions ( $p$ value are all less than $0.05, \mathrm{OR}>1$ ); questionnaire item "attracting high achievers in STEM to primary school teaching" (U1) is negatively related to platform $(\mathrm{OR}<1)$. Multivariate logistic regression in Table 6 showed only BQ1 (OR (95\%CI) 4.171 (1.453, 11.977)), ITQ3 (OR (95\%CI)10.659 (3.801, 29.892)), and ITQ5 (OR (95\%CI) $4.108(1.410,11.967))$ which are all positively related to platform, and U1 is still negatively related to platform (OR (95\%CI) 0.298 (0.116, 0.766)). Univariate logistic regression revealed BQ1-3, ITQ4-5 are all positively related to future needs $(\mathrm{OR}>1), \mathrm{U} 1$ is still negatively related to future needs, only two variables (BQ1, ITQ4) in multivariate logistic regression were found be positively related.

These results indicate that the pre-service teachers' present understanding of STEM is limited; however, their beliefs and intentions show they recognise the need for capacity to teach STEM in the future. There is high significance in the need for resources in terms of beliefs and with creativity and innovations regarding their intentions.

Since there is minimal understanding about STEM, the connections were made with beliefs and intentions towards what is happening now and future needs, based on the pre-service teachers' responses. Then, the SEM model was used to identify this complex relationship.

Figure 5 provides the final modified SEM model by these pre-service teachers. We carried out bootstrapping to check the significance of each indicator (200 samples, 100 Cases). Based on Fig. 5, we found all of the loadings and inner path coefficients were significant at 5\% level of significance. The SEM model depicted in Fig. 5 
Capacity Building on STEM teaching and learning in primary schools

\begin{tabular}{|c|c|c|}
\hline Beliefs about STEM & $\begin{array}{c}\text { Positions of } \\
\text { Understanding of STEM }\end{array}$ & $\begin{array}{c}\text { Intentions of teaching } \\
\text { STEM }\end{array}$ \\
\hline 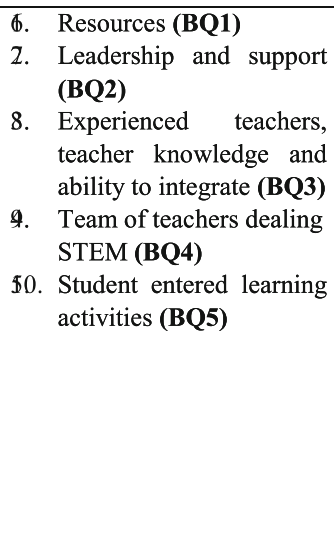 & $\begin{array}{l}\text { 6. } \begin{array}{l}\text { Confidence and } \\
\text { competence to teach } \\
\text { STEM (UQ1) }\end{array} \\
\text { 2. } \begin{array}{l}\text { Confident with } \\
\text { mathematics not with } \\
\text { science and technology to } \\
\text { teach STEM (UQ2) }\end{array} \\
\text { 8. Underprepared and lack } \\
\text { of knowledge to teach } \\
\text { STEM (UQ3) } \\
\text { Not confident with } \\
\text { science to teach STEM } \\
\text { (UQ4) } \\
\text { \$0. Not at all confident to } \\
\text { teach STEM (UQ5) }\end{array}$ & $\begin{array}{l}\text { 6. Teach S, T, M \& E in } \\
\text { curriculum (ITQ1) } \\
\text { 2. Confident teachers in } \\
\text { dealing with STEM } \\
\text { (ITQ2) } \\
\text { 8. Student participation and } \\
\text { activity oriented teaching } \\
\text { and learning (ITQ3) } \\
\text { 9. Creativity, innovation } \\
\text { and interdisciplinary } \\
\text { focus in teaching and } \\
\text { learning STEM (ITQ4) } \\
\text { 50. STEM should be a } \\
\text { specialised and } \\
\text { compulsory subject } \\
\text { (ITQ5) }\end{array}$ \\
\hline
\end{tabular}

Fig. 4 Overall representation of beliefs, understandings, and intentions of capacity building of STEM among pre-service teachers

includes the loadings of the measurement and path coefficients of the structure model. Table 7 presents the evaluation of the measurement model and loading coefficients, which showed that all factor loadings were higher than 0.4 , the $\mathrm{CR}$ for each latent variable was above or close to 0.7, and the AVE was always greater than 0.5 . Therefore, the measurement models were considered acceptable for the evaluation of the SEM.

The $R^{2}$, which is used to measure the model's explanatory power, was 0.437 for "Now", indicating that $43.7 \%$ of the total variance in the proportion was explained by "Belief" and "Intention", while $26.7 \%$ of the total variance in "Future" was explained by "Belief" and "Intention", and only $13.4 \%$ of the total variance in "Intention" was explained by "Belief". All of the path coefficients were statistically significant $(p<0.05)$ based on bootstrapping. The total effect of "Belief" to "Now" is $0.482(t=6.593)$, "Intention" to "Now" is $0.487(t=5.150)$, "Belief" to "Future" is $0.400(t=5.149)$, "Intention" to "Future" is 0.353 $(t=3.108)$, and "Belief" to "Intention" is $0.367(t=4.205)$.

Based on these results, it is evident that the platform developed for teaching STEM based on experience in their teaching degree is limited; however, they have positive intentions to take up STEM. They are not seeing any positive initiative at schools, and they have limited confidence to teach science. However, they were suggesting that they should be provided with more opportunities to teach STEM.

Based on this body of evidence, the following overall model can be formulated and this model provides the connections between the platform of primary pre-service teachers towards their capacity to deal with STEM in their future career. At present, teachers are trained with limited understanding and experience of STEM in primary schools; however, they have optimism that is clearly expressed in their beliefs and intentions. Examples of aspects mentioned in terms of beliefs and intentions are resources, leadership, ability to integrate, innovations, and interdisciplinary approaches. This seems an expression of their genuine concern for STEM education and a true reflection. They were very explicit in mentioning their limited understanding. The reflections of what is happening now and what is needed in the future were based on their overall experience of their course including professional placements, and this seems realistic. Statistical significance of the responses provides authenticity to this overall model (Fig. 6) of the platform towards the capacity for teaching STEM among future primary teachers.

\section{Implications of this study}

Future teachers in this study revealed some of the gaps existing, based on their university education experience and teaching practice in schools during practicum. Based on this, the following future practices could be considered in teacher preparation to build confident, competent, and skilled teachers in STEM. This could lead to the production of twenty-first century skilled workforce in STEM-related fields.

- There should be experiences in STEM for future teachers so that they can apply knowledge and skills in actual practices 
Table 5 Platform logistic regression results

\begin{tabular}{|c|c|c|c|c|}
\hline Variable & Unadjusted OR & $p$ value & Adjusted OR & $p$ value \\
\hline B1 & $0.761(0.478,1.212)$ & 0.250 & & \\
\hline B2 & $0.915(0.637,1.315)$ & 0.631 & & \\
\hline B3 & $0.764(0.408,1.431)$ & 0.401 & & \\
\hline B4 & $0.825(0.394,1.725)$ & 0.608 & & \\
\hline B5 & $0.796(0.518,1.222)$ & 0.297 & & \\
\hline BQ1 (1vs.0) & $3.913(1.660,9.223)^{*}$ & 0.002 & $4.171(1.453,11.977)^{*}$ & 0.008 \\
\hline BQ2 (1vs.0) & $3.175(1.415,7.120)^{*}$ & 0.005 & & \\
\hline BQ3 (1vs.0) & $4.384(1.954,9.838)^{*}$ & $<0.001$ & & \\
\hline BQ4 (1vs.0) & $4.601(1.939,10.921)^{*}$ & 0.001 & & \\
\hline BQ5 (1vs.0) & $3.351(1.472,7.626)^{*}$ & 0.004 & & \\
\hline U1 & $0.374(0.184,0.762)^{*}$ & 0.007 & $0.298(0.116,0.766)^{*}$ & 0.012 \\
\hline U2 & $0.782(0.441,1.388)$ & 0.401 & & \\
\hline U3 & $1.147(0.753,1.747)$ & 0.522 & & \\
\hline U4 & $0.828(0.531,1.291)$ & 0.405 & & \\
\hline U5 & $1.164(0.764,1.771)$ & 0.480 & & \\
\hline UQ (1vs.0) & $1.448(0.363,5.780)$ & 0.600 & & \\
\hline IT1 & $1.397(0.858,2.275)$ & 0.179 & & \\
\hline IT2 & $0.652(0.408,1.041)$ & 0.073 & & \\
\hline IT3 & $0.852(0.539,1.347)$ & 0.493 & & \\
\hline IT4 & $0.831(0.564,1.223)$ & 0.348 & & \\
\hline IT5 & $1.035(0.669,1.602)$ & 0.877 & & \\
\hline ITQ1 (1vs.0) & $4.069(1.787,9.264)^{*}$ & 0.001 & & \\
\hline ITQ2 (1vs.0) & $7.179(3.091,16.675)^{*}$ & $<0.001$ & & \\
\hline ITQ3 (1vs.0) & $9.651(3.952,23.568)^{*}$ & $<0.001$ & $10.659(3.801,29.892)^{*}$ & $<0.001$ \\
\hline ITQ4 (1vs.0) & $5.536(2.367,12.948)^{*}$ & $<0.001$ & & \\
\hline ITQ5 (1vs.0) & $3.182(1.399,7.238)^{*}$ & 0.006 & $4.108(1.410,11.967)^{*}$ & 0.01 \\
\hline
\end{tabular}
${ }^{*} p<0.05$

- Ability to integrate knowledge and understanding of disciplines to STEM-related experiences

- Integrated knowledge should have sound pedagogical practices and coherence in the curriculum to implement best practices connected to daily life in STEM-related issues

- There is a need for ongoing professional development in STEM for all teachers

- Schools should link school and out-of-school experiences to STEM-related activities.

These practices are basically coming under STEM knowledge base, policies, and practices. Reports like the National Research Council (NRC 2015) and Next Generation Science Standards (NGSS Lead States 2013) highlight the importance of STEM knowledge base at all levels. Policies of STEM education would present clarity with knowledge integration and curricular coherence (Linn et al. 2008) so that teachers would be comfortable in teaching STEM with an integrated and interdisciplinary focus. In this context, it would be considered to have connections with STEM industry to showcase STEM actual practice and STEM knowledge in schools. This would provide effective knowledge and disciplinary integration within classroom practices.

\section{Limitations of this study}

The present study used self-reported beliefs, understandings, and intentions of pre-service teachers as a platform. The understanding of STEM disciplines like science and mathematics seems limited and is reflected in their quantitative responses. Qualitative responses from which categories are formulated concur this. Analysis of the data revealed that there is a relationship between beliefs and intentions rather than beliefs, understandings, and intentions. We have taken extreme care in the analysis of the data using appropriate statistical techniques. The reality is that this sample of preservice teachers represent only one campus in a metropolitan city 
Table 6 Future confidence and capacity logistic regression result

\begin{tabular}{|c|c|c|c|c|}
\hline Variable & Unadjusted OR & $p$ value & Adjusted OR & $p$ value \\
\hline B1 & $0.708(0.392,1.276)$ & 0.250 & & \\
\hline B2 & $0.962(0.623,1.484)$ & 0.860 & & \\
\hline B3 & $1.463(0.720,2.972)$ & 0.293 & & \\
\hline B4 & $1.213(0.531,2.771)$ & 0.647 & & \\
\hline B5 & $1.078(0.652,1.780)$ & 0.770 & & \\
\hline BQ1(1vs.0) & $3.483(1.340,9.052)^{*}$ & 0.010 & $3.315(1.196,9.184)^{*}$ & 0.021 \\
\hline BQ2(1vs.0) & $2.937(1.154,7.472)^{*}$ & 0.024 & & \\
\hline BQ3(1vs.0) & $4.384(1.954,9.838)^{*}$ & $<0.001$ & & \\
\hline BQ4(1vs.0) & $2.718(0.987,7.485)$ & 0.053 & & \\
\hline BQ5(1vs.0) & $0.713(0.286,1.775)$ & 0.467 & & \\
\hline U1 & $0.750(0.356,1.580)$ & 0.449 & & \\
\hline U2 & $0.566(0.269,1.191)$ & 0.134 & & \\
\hline U3 & $1.370(0.833,2.253)$ & 0.215 & & \\
\hline U4 & $1.063(0.641,1.763)$ & 0.814 & & \\
\hline U5 & $1.439(0.855,2.420)$ & 0.170 & & \\
\hline UQ (1vs.0) & $0.606(0.148,2.490)$ & 0.487 & & \\
\hline IT1 & $1.086(0.608,1.940)$ & 0.780 & & \\
\hline IT2 & $1.030(0.603,1.758)$ & 0.914 & & \\
\hline IT3 & $1.031(0.601,1.768)$ & 0.913 & & \\
\hline IT4 & $0.968(0.618,1.520)$ & 0.891 & & \\
\hline IT5 & $0.955(0.557,1.638)$ & 0.868 & & \\
\hline ITQ1 (1vs.0) & $2.468(0.970,6.279)$ & 0.058 & & \\
\hline ITQ2 (1vs.0) & $2.482(0.983,6.264)$ & 0.054 & & \\
\hline ITQ3 (1vs.0) & $2.274(0.896,5.769)$ & 0.084 & & \\
\hline ITQ4 (1vs.0) & $6.650(2.101,21.045)^{*}$ & 0.001 & $6.441(1.992,20.831)^{*}$ & 0.002 \\
\hline ITQ5 (1vs.0) & $4.952(1.568,15.641)^{*}$ & 0.006 & & \\
\hline
\end{tabular}

${ }^{*} p<0.05$

in Australia. Care should be taken in broader generalisation based on this study.

Regarding the sample size, there is no consensus in the literature what would be an appropriate sample size for using SEM. Some evidence exists that simple SEM models could be meaningfully tested even if the sample size is quite small (Hoyle and Kenny 1999; Marsh and Hau 1999), but usually, $N=100-150$ is considered the minimum sample size for conducting SEM (Tinsley and
Tinsley 1987; Anderson and Gerbing 1988; Ding et al. 1995; Tabachnick and Fidell 2001), and this study has a sample of 119 and is appropriate to use SEM model.

\section{Conclusions}

Teachers' platform of knowledge, confidence, and efficacy for teaching STEM influences the students learning and their classroom practices (Nadelson et al. 2013), and the teachers' ability in integrating background knowledge

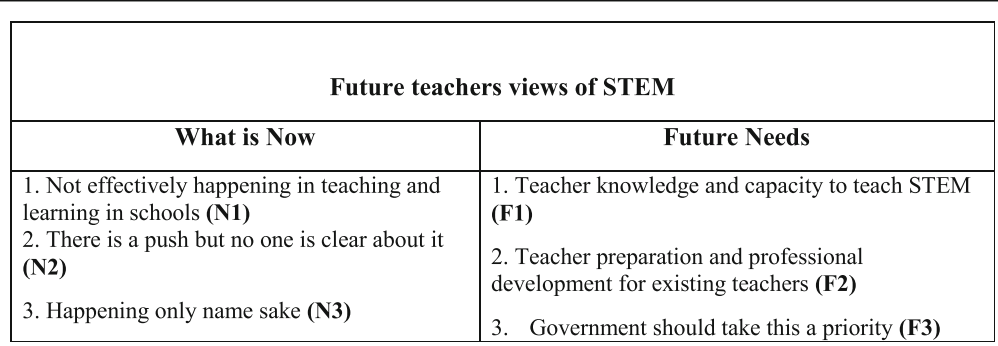

Fig. 5 SEM model of beliefs and intentions towards what is happening now and future needs 
Table 7 Results summary of the SEM model

\begin{tabular}{|c|c|c|c|c|c|}
\hline Variable & Loading & Composite Reliability (CR) & Average Variance Extracted (AVE) & $R^{2}$ & $t$-statistics \\
\hline Belief & & 0.862 & 0.558 & & \\
\hline BQ1 & 0.712 & & & & 8.226 \\
\hline BQ2 & 0.736 & & & & 9.740 \\
\hline BQ3 & 0.834 & & & & 28.674 \\
\hline $\mathrm{BQ} 4$ & 0.777 & & & & 16.154 \\
\hline BQ5 & 0.664 & & & & 8.569 \\
\hline Intention & & 0.855 & 0.600 & 0.134 & \\
\hline ITQ1 & 0.779 & & & & 13.732 \\
\hline ITQ2 & 0.825 & & & & 16.552 \\
\hline ITQ3 & 0.871 & & & & 27.673 \\
\hline ITQ4 & 0.597 & & & & 6.347 \\
\hline Now & & 0.871 & 0.694 & 0.437 & \\
\hline N1 & 0.874 & & & & 27.022 \\
\hline N2 & 0.890 & & & & 34.475 \\
\hline N3 & 0.725 & & & & 12.899 \\
\hline Future & & 0.800 & 0.578 & 0.267 & \\
\hline F1 & 0.771 & & & & 8.834 \\
\hline F2 & 0.604 & & & & 4.521 \\
\hline F3 & 0.879 & & & & 19.759 \\
\hline
\end{tabular}

of technological pedagogical content knowledge to a STEM curriculum seems a challenge to pre-service and in-service teachers (Hofer and Grandgenett 2012). The demands of a twenty-first century education include challenges to the existing practices, and there is a need to make overall make shifts across education and within the primary level (NRC 2015). Teachers' beliefs and worldview have a great influence on teaching methods and strategies used (Davis 2003). There is a gap between beliefs, understandings, and intentions to teach with capacity and confidence, and to bridge this gap, there is a need for innovative practices in teacher preparation and teacher professional development (Barak 2014). Though there are gender differences in STEM education (Pasha-Zaidi and Afari 2016), however, professional participation studies have shown that all perform equally
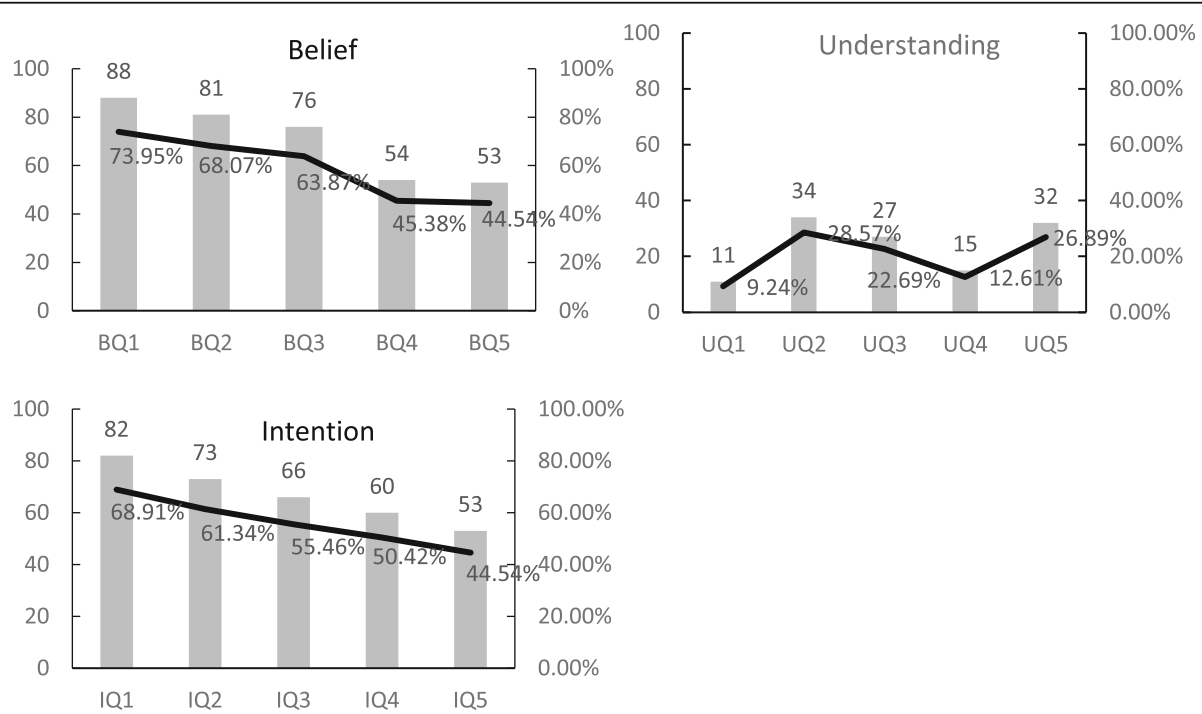

Fig. 6 Overall model of STEM among future teachers' platform towards capacity building regarding STEM 
well (Bergeron and Gordon 2017). In primary schools, there are more female teachers than male teachers, and in this research, there were more female pre-service teachers as participants.

This study revealed that future teachers have strongly held beliefs and intentions for teaching STEM in their future classrooms. The reality they face is the lack of understanding of connections to integrate science, mathematics, engineering, and technology as well as pedagogical approaches to deal STEM based on real-life situations. For building an effective STEM capacity among future teachers, there is a need for policies of STEM that are based on the four-dimensional framework advocated by Bybee (2013). This would enable the development of resources, leadership, integration, and team teaching as stated by the future teachers in this study to become a reality. The complexities associated with training of teachers, changing classroom practices to achieve an ideal STEM focus, require innovations and decisions from all levels of individuals and governments (Fensham 2016). There should be future funded placements in higher education institutions so future teachers can experience place-based STEM pedagogies to build the capacity in dealing with STEM (Adams et al. 2014). Overall, it is indicated that present university courses or placements are not adequately preparing pre-service teachers to teach STEM in primary schools. Pre-service teachers may have adequate capacity to deal with literacy and numeracy; however, they find it sometimes difficult to deal with science in primary schools in Australia. Pre-service teachers reported that they have not experienced any STEM-based program during their practicum experience indicating that only in few schools it is happening in Australia. Pre-service teachers have intentions to integrate STEM and provide their students with STEM experience; however, they need professional development. This suggests that there should be STEM-focused experience in university teacher education degree program. It is essential to formulate a course work in STEM capable of integrating disciplines, provide understanding of pedagogical approaches and capable of connecting to real life relevance with 21 st century competencies.

\section{Abbreviations}

AVE: Average variance extracted; CR: Composite reliability; OLS: Ordinary least squares; PLS: Partial least squares; SEM: Structural equation model

\section{Acknowledgements}

This research was supported in part by The Statistics Consultancy Platform and Social Research Assistance Platform of La Trobe University, Melbourne, Australia.

\section{Funding}

Authors declare that there is no funding for this research and wavier is approved by the journal.

\section{Availability of data and materials}

Please contact author for data requests. (This part is included in the manuscript as well before reference section).

\section{Declaration}

Authors declare that this manuscript is based on original research conducted by the Authors and ethics is cleared for this research.

\section{Authors' contributions}

This research is conducted by a team of researchers with specified STEM areas, and the following are their major contributions. PK is the main author who has a science background and contributed to the STEM aspects of this research based on science. XL is a mathematics and statistics educator who looked at the analysis of data and results. GP is a design and technology educator and contributed to the technological aspects. MB is a vocational and curriculum specialist and contributed to the curriculum aspects of STEM. All authors read and approved the final manuscript.

\section{Ethics approval and consent to participate}

Ethics for the research is covered by the Human Ethics committee of the La Trobe University, Australia. Ethics Approval No. E16-024 (This part is included in the manuscript as well before reference section).

\section{Competing interests}

The authors declare that they have no competing interests.

\section{Publisher's Note}

Springer Nature remains neutral with regard to jurisdictional claims in published maps and institutional affiliations.

\section{Author details}

${ }^{1}$ School of Education, College of Arts, Social Sciences and Commerce (ASSC), La Trobe University, Bundoora, Melbourne, VIC 3086, Australia. ${ }^{2}$ Department of Mathematics and Statistics, La Trobe University, Melbourne, Australia.

Received: 10 September 2018 Accepted: 21 February 2019

Published online: 11 March 2019

\section{References}

Abell, S. K. (2007). Research on science teacher knowledge. In S. K. Abell \& N. G. Lederman (Eds.), Handbook of research on science education (pp. 1105-1149). Mahwah: Lawrence Erlbaum.

Abell, S. K. (2008). Twenty years later: does pedagogical content knowledge remain a useful idea? International Journal of Science Education, 30(10), 14051416.

Adams, A. E., Miller, B. G., Saul, M., \& Pegg, J. (2014). Supporting elementary preservice teachers to teach STEM through place-based teaching and learning experiences. Electronic Journal of Science Education, 18(5).

Aizen, I., \& Fishbein, M. (1980). Understanding attitudes and predicting social behaviour. Englewood Cliffs: Prentice-Hall.

Anderson, J. C., \& Gerbing, D. W. (1988). Structural equation modelling in practice: a review and recommended two step approach. Psychological Bulletin, 103, $411-423$.

Anderson, T. (2004). Toward a theory of online learning. In T. Anderson \& F. Elloumi (Eds.), Theory and practice of online learning (pp. 33-60). Athabasca: Athabasca University.

Apple Inc. (2010). Challenge Based Learning: a classroom guide. Retrieved from: https://images.apple.com/education/docs/CBL_Classroom_Guide_Jan_2011. pdf

Barak, M. (2014). Closing the gap between attitudes and perceptions about ICTenhanced learning among pre-service STEM teachers. Journal of Science Education and Technology, 23(1), 1-14.

Bergeron, L., \& Gordon, M. (2017). Establishing a STEM pipeline: trends in male and female enrolment and performance in higher level secondary STEM courses. International Journal of Science and Mathematics Education, 15(3), 433-450.

Berry, A., Loughran, J., \& van Driel, J. H. (2008). Revisiting the roots of pedagogical content knowledge. International Journal of Science Education, 30(10), 12711279.

Bybee, R. W. (2013). The case for STEM education: challenges and opportunities. Arlington, VA: NSTA Press, 
Charmaz, K. (2005). Grounded theory in the $21^{\text {st }}$ century: Applications for advancing social justice studies (pp. 507-537). In N. Denzin \& Y.S. Lincoln (eds.). The Sage Handbook of Qualitative Research. Third Edition. Thousand Oaks: CA. SAGE Publications.

Chin, W. W. (1998). The partial least squares approach to structural equation modeling. In G. A. Marcoulides (Ed.), Modern methods for business research (pp. 295-336). Mahwah: Lawrence Erlbaum.

Chin, W. W., \& Newsted, P. R. (1999). Structural equation modeling analysis with small samples using partial least squares. In R. H. Hoyle (Ed.), Statistical strategies for small sample research (pp. 307-341). Thousand Oaks: Sage.

Civil, M. (2016). Stem learning research through a funds of knowledge lens. Cultural Studies of Science Education, 11(1), 41-59.

Compeau, D. R., \& Higgins, C. A. (1995). Application of social cognitive theory to training for computer skills. Information Systems Research, 6(2), 118-143.

Davis, K. S. (2003). "Change is hard": what science teachers are telling us about reform and teacher learning of innovative practices. Science Education, 87(1), $3-30$.

Dede, C. (2009). Immersive interfaces for engagement and learning. Science, 323(5910), 66-69.

Dede, C. (2013). Connecting the dots: new technology-based models for postsecondary learning. Educause Review, 48(5), 32-52.

Dierking, L. D., \& Falk, J. H. (2016). 2020 vision: envisioning a new generation of STEM learning research. Cultural Studies of Science Education, 11(1), 1-10.

Ding, L., Velicer, W. F., \& Harlow, L. L. (1995). Effects of estimation methods, number of indicators per factor, and improper solutions on structural equation modeling fit indices. Structural Equation Modeling, 2, 119-144.

Falk, J. H., Dierking, L. D., Staus, N. L., Wyld, J. N., Bailey, D. L., \& Penuel, W. R. (2016). The synergies research-practice partnership project: a 2020 vision case study. Cultural Studies of Science Education, 11(1), 195-212.

Falk, J. H., \& Needham, M. D. (2013). Factors contributing to adult knowledge of science and technology. Journal of Research in Science Teaching, 50(4), 431-452.

Fensham, P. J. (2015). Connoisseurs of science: a next goal for science education? In D. Corrigan, C. Buntting, J. Dillon, A. Jones, \& R. Gunstone (Eds.), The future in learning science: what's in it for the learner? (pp. 35-59). Dordrecht: Springer.

Fensham, P. J. (2016). The future curriculum for school science: what can be learnt from the past? Research in Science Education, 46(2), 165-185.

Fernández-Manzanal, R., Rodríguez-Barreiro, L., \& Carrasquer, J. (2007). Evaluation of environmental attitudes: analysis and results of a scale applied to university students. Science Education, 91(6), 988-1009.

Foundation for Young Australians. (2017). The new work smarts: thriving in the new work order. Sydney: Foundation for Young Australians Retrieved from. www.fya.org.au.

Foundation for Young Australians (FYA). (2015). The new work order: ensuring young Australians have skills and experience for the jobs of the future, not the past. Melbourne: Foundation of Young Australians Retrieved from. www.fya.org.au.

Graube, G., \& Mammes, I. (2018). Industry involvement in technology education. In M. de Vries (Ed.), Handbook of technology education. Dordrecht: Springer.

Hajkowicz, S., Reeson, A., Rudd, L., Bratanova, A., Hodgers, L., Mason, C., \& Boughen, N. (2016). Tomorrow's digitally enabled workforce: megatrends and scenarios for jobs and employment in Australia over the coming years. Brisbane: CSIRO.

Hofer, M., \& Grandgenett, N. (2012). TPACK development in teacher education: a longitudinal study of preservice teachers in a secondary M.A.Ed. program. Journal of Research on Technology in Education, 45(1), 83-106.

Holstein, J. A., \& Gabrium, J. F. (2005). Interpretive practice and social action. In N. K. Denzin \& Y. S. Lincoln (Eds.),The Sage Handbook of Qualitative Research, pp (483-505). Thousand Oaks: CA.SAGE Publications.

Hoyle, R. H., \& Kenny, D. A. (1999). Sample size, reliability, and tests of statistical mediation. In R. H. Hoyle (Ed.), Statistical strategies for small sample research (pp. 195-222). Thousand Oaks: Sage.

Johnson, L., \& Adams, S. (2011). Challenge based learning: the report from the implementation project. Austin: The New Media Consortium.

Kalantzis, M., \& Cope, B. (2012). New learning: elements of a science of education. Melbourne: Cambridge University Press.

Kitchen, J. A., Sonnert, G., \& Sadler, P. M. (2018). The impact of college- and university-run high school summer programs on students' end of high school STEM career aspirations. Science Education, 1, 1-9.

Kurup, P.M, Brown, M., Powell, G., \& Li X. (2017). Future primary teachers' beliefs, understandings and intentions to teach STEM, IAFOR Journal of Education, Volume 5 - Special Issue. Summer, 2017.
Lee, E., Brown, M. N., Luft, J. A., \& Roehrig, G. H. (2007). Assessing beginning secondary science teachers' PCK: pilot year results. School Science and Mathematics, 107(2), 52-60.

Levinson, R., Kent, P., Pratt, D., Kapadia, R., \& Yogui, C. (2012). Risk-based decision making in a scientific issue: a study of teachers discussing a dilemma through a micro world. Science Education, 96(2), 212-233.

Linn, M. C., Kali, Y., Davis, E. A., \& Horwitz, P. (2008). Policies to promote coherence. In Y. Kali, M. C. Linn, \& J. E. Roseman (Eds.), Designing coherent science education, implications for curriculum, instruction and policy (pp. 201210). Columbia University: Teachers College Press.

Liu, S.-Y., Lin, C.-S., \& Tsai, C.-C. (2011). College students' scientific epistemological views and thinking patterns in socioscientific decision making. Science Education, 95(3), 497-517.

Marsh, H. W., \& Hau, K. T. (1999). Confirmatory factor analysis: strategies for small sample sizes. In R. H. Hoyle (Ed.), Statistical strategies for small sample size (pp. 251-306). Thousand Oaks: Sage Publications.

Nadelson, L. S., Callahan, J., Pyke, P., Hay, A., Dance, M., \& Pfiester, J. (2013). Teacher STEM perception and preparation: Inquiry-based STEM professional development for elementary teachers. Journal of Educational Research, 106(2), 157-168.

National Research Council. (2015). Identifying and supporting productive STEM programs in out-of-school settings. Washington: The National Academies Press.

NGSS Lead States. (2013). Next generation science standards: for states, by states. Washington: The National Academies Press.

Pasha-Zaidi, N., \& Afari, E. (2016). Gender in STEM education: an exploratory study of student perceptions of math and science instructors in United Arab Emirates. International Journal of Science and Mathematics Education, 14(7), 1215-1231.

Perkins, D. (2014). Future wise: educating our children for a changing world. New York: Wiley.

Prinsley, R., \& Johnston, E. (2015). Transforming STEM teaching in Australian primary schools: everybody's business. Canberra, Australia: Australian Government, Office of the Chief Scientist.

Rahm, J. (2016). Stories of learning, identity, navigations and boundary crossings in STEM in non-dominant communities: new imaginaries for research and action. Cultural Studies of Science Education, 11(1), 61-75.

Roth, W.-M., \& Lee, S. (2004). Science education as/for participation in the community. Science Education, 88(2), 263-291.

Ryder, J. (2001). Identifying science understanding for functional scientific literacy. Studies in Science Education, 36, 1-44.

Schreiner, C., Henriksen, E. K., \& Kirkeby Hansen, P. J. (2005). Climate education: empowering today's youth to meet tomorrow's challenges. Studies in Science Education, 41, 3-50.

Schultz, P. W. (2001). The structure of environmental concern. Concern for self, other people, and the biosphere. Journal of Environmental Psychology, 21(4), 327-339.

Shah, A. M., Wylie, C., Gitomer, D., \& Noam, G. (2018). Improving STEM program quality in out- of-school time: tool development and validation. Science Education, 1, 1-22.

Slaughter, R. (1996). The knowledge base of futures studies. Melbourne: DDM.

Storksdieck, M. (2016). Critical information literacy as core skill for lifelong STEM learning in the 21st century: reflections on the desirability and feasibility for widespread science media education. Cultural Studies of Science Education, $11(1), 167-182$.

Tabachnick, B. G., \& Fidell, L. S. (2001). Using multivariate statistics (4th ed.). Boston: Allyn \& Bacon.

Thomm, E., \& Bromme, R. (2012). "It should at least seem scientific!" textual features of "scientificness" and their impact on lay assessments of online information. Science Education, 96(2), 187-211.

Tinsley, H. E., \& Tinsley, D. J. (1987). Uses of factor analysis in counseling psychology research. Journal of Counseling Psychology, 34, 414-424.

Tobin, K. (2016). Collaborating on global priorities: Science education for everyone-any time and everywhere. Cultural Studies of Science Education, 11(1), 27-40.

Walker, D. (1971). A naturalistic model of curriculum development. School Review, $80(1), 51-65$

Zeidler, D. L. (2016). STEM education: A deficit framework for the twenty first century? A sociocultural socioscientific response. Cultural Studies of Science Education, 11(1), 11-26. 